\title{
Enfermedad Inflamatoria Pélvica
}

Comentarios a dos años y medio de estadística en el Servicio de Ginecología. - Hospital San Juan de Dios - Bogotá, D. E.

Dres.: Alvaro Espinosa y Espinosa, Bernardo Handzer y Luis Alba P.*

Hace quince años, con el advenimiento de las sulfas, y luego con el de los antibióticos de más y mejor eficacia, creíamos que los procesos inflamatorios pelvianos desaparecerían casi por completo de la patología genital femenina. (1-2)

De ahí que los trabajos y estudios con relación a esta entidad son poco numerosos al presente, y cuando se presentan se dirigen generalmente a la tuberculosis genital, sobre la cual abunda la literatura.

Pero nuestra experiencia en diez y ocho años de trabajar en este campo, y el análisis del presente estudio comparado con uno de hace quince años, efectuado por uno de nosotros, (A. E. E.) (2) nos lleva a la conclusión de que andamos equivocados, y que la infección pélvica persiste igual en nuestro medio hospitalario, a la época de terapia antibiótica. Entonces, encontrábamos en la estadísítica un $17.4 \%$ en relación con las demás entidades ginecológicas y en el presente encontramos un $10.07 \%$ al estudio de la actual estadística.

Si bien es cierto que dominamos hoy más fácilmente la infección, no es menos real que los procesos inflamatorios pelvianos persisten y aún hemos vuelto a presenciar grandes masas inflamatorias en nuestros hospitales. Lo real es que la profilaxis y educación social no han corrido parejas con los adelantos de la ciencia en cuanto a tratamiento.

Por otra parte, el abuso de los antibióticos ha dado lugar a resistencias bacterianas. y aun a sensibilizaciones que han llevado en ocasiones a la muerte.

El presente estudio crítico comprende 195 historias clínicas en un período de $2 \frac{1}{2}$ años, desde el $1^{\text {o }}$ de Enero de 1959 , hasta

\footnotetext{
* Del Departamento de Ginecolcgía. Hospital San Juan de Dios de Bogotá.
} 
el 30 de Junio de 1961, en pacientes que ingresaron al servicio con diagnóstico de enfermedad inflamatoria pélvica.

\section{CUADRO $\mathrm{N}^{0} 1$ \\ INFECCIONES PELVICAS}

Edad de las Pacientes

Años

15 a 20

20 a 25

25 a 30

30 a 35

35 a 40

40 a 45

45 a 50

50 a 55

60 años

TOTAL

Casos
16
48
48
32
22
16
10
2
1
195

Caso

48

48

32

22

16

10

2

95

$\%$
$8.2 \%$
$24.6 \%$
$24.6 \%$
$16.4 \%$
$11.2 \%$
$8.2 \%$
$5.10 \%$
$1.02 \%$
$0.51 \%$
$99.82 \%$

CUADRO No 2

INFECCIONES PELVICAS

Antecedentes obstétricos

Paridad

Nulíparas

Primíparas

$\begin{array}{llllll}1 & \text { a } & 3 & \ldots & 58\end{array}$

Multíparas

3 a $5 \ldots 33$

5 o más .. 20
Casos

45

39

111

195
Porcentaje

$23.01 \%$

$20 \%$

$56.9 \%$

\section{ABORTOS}

uno

dos

tres

tres o más

Ectópico

$\begin{array}{r}37 \\ 16 \\ 3 \\ 3 \\ \hline 59\end{array}$

1
$99.91 \%$

$18.9 \%$

$8.11 \%$

$1.54 \%$

$1.54 \%$

$30.09 \%$

$0.51 \%$ 
En 1946 hacíamos el mismo comentario (2) a 187 historias en un período semejante de tiempo, del $1^{\circ}$ de marzo de 1943 al $1^{\circ}$ de marzo de 1946. Entonces no disponíamos sino de quimioterápicos del tipo de las sulfas. vacunas, y se iniciaba la era antibiótica sobre la cual no teníamos experiencia. La comparación de estos dos períodos de tiempo nos enseña que las aseveraciones que hemos hecho son justas y acertadas.

Todas las pacientes, una vez efectuado el diagnóstico, se sometieron a tratamiento médico con antibióticos, y las medidas generales conocidas desde tiempo inmemorial, de reposo absoluto, hidratación, etc. El análisis de los datos de estas historias es lo que presentamos hoy haciendo comparaciones con otras estadísticas nacionales y extranjeras.

\section{$E D A D$}

Referente a la edad de la pacientes (Cuadro número uno), vemos que ellas continúan presentándose con mayor frecuencia en el período de mayor actividad genital de la mujer, es decir, de los veinte a los cuarenta años, disminuyendo en esa época hasta los cincuenta, y siendo casi sin importancia más allá de esa edad.

\section{ANTECEDENTES OBSTETRICOS}

Los antecedentes de paridad nos enseñan lo ya conocido (Cuadro número dos), que la mayor cantidad de pacientes son multíparas, dándonos un $56.9 \%$, lo que unido a la frecuencia en las primíparas nos lleva a un porcentaje del $76 \%$.

En las nulíparas hallamos un porcentaje del $23 \%$, que indudablemente tenemos que achacar a la etiología gonocóccica en la mayoría de los casos. Es $€ n$ ellas que generalmente se presenta la TBC genital.

Posiblemente hay algunos casos más de abortos, pero como existen aún historias muy deficientes en lo tocante a anamnesis, no se pudieron comprobar sino 59 casos que representan un $30.09 \%$, cifra por otra parte no de escaso significado estadístico, pero que no requiere comentarios. 
CUADRO No 3

ANTECEDENTES GINECOLOGICOS

a) Trastornos menstruales

Metrorragias

Casos

$\%$

Polihipermenorrea

Hipermenorrea

Polimenorrea

Amenorrea (menopáusica 1)

Polihipomenorrea

Hipomenorrea

Olihipomenorrea

Oligomenorragia

Oligomenorrea

\begin{tabular}{rr}
26 & $13.33 \%$ \\
8 & $4.10 \%$ \\
6 & $3.07 \%$ \\
4 & $2.05 \%$ \\
5 & $2.53 \%$ \\
1 & $0.51 \%$ \\
2 & $1.02 \%$ \\
1 & $0.51 \%$ \\
1 & $0.51 \%$ \\
1 & $0.51 \%$ \\
\hline 55 & $28.20 \%$ \\
17 & $8.71 \%$ \\
133 & $68.20 \%$ \\
& \\
1 & $0.51 \%$ \\
2 & $1.02 \%$ \\
2 & $1.02 \%$ \\
1 & $0.51 \%$
\end{tabular}

b) ALGOMENORREA

c) FLUJO GENITAL

d) Esterilidad

Primaria

Secundaria

e) Algopareunia

f) Tensión premenstrual

\section{CUADRO No 4 \\ INFECCIONES PELVICAS \\ ETIOLOGIA}

$\begin{array}{lll}\text { Bacterias gram negativas } & \text { aisladas } & 7 \\ & \text { asociadas } & 12 \\ \text { Estafilococo } & \text { aislado } & 2 \\ & \text { asociado } & 10 \\ \text { Bacterias gram positivas } & \text { aisladas } & 1 \\ & \begin{array}{ll}\text { asociadas } \\ \text { confirmado }\end{array} & 10\end{array}$


T. B. C. (Koch)

Escherichia C.

Trichomonas

Diplococus Neisser

Enterococos asociados

Salmonella asociada

Estreptococo

Espirila de Vincent

Historias sin dato
10

$\begin{array}{cc}? & 2 \\ \text { aislada } & 3\end{array}$

asociada 6

aislada 2

asociada 6

aislado 3

asociado. 2

9

$4.59 \%$

8

$4.08 \%$

5

$2.55 \%$

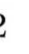

4

$\begin{array}{rr}4 & 2.04 \% \\ 1 & 0.51 \% \\ 1 & 0.51 \% \\ 1 & 0.51 \% \\ 113 & 57.6 \%\end{array}$

\section{ANTECEDENTES GINECOLOGICOS}

En el Cuadro tres, observamos que el flujo es el síntoma más notorio en estos casos, como era de esperarse, y que vino a comprobarse más por el examen pélvico que por el interrogatorio. Recordemos que en nuestro medio, la mujer no le da a este síntoma ninguna trascendencia, y lo considera en la mayoría de los casos como normal. Volveremos sobre este punto al comentar el Cuadro siguiente.

Los trastornos menstruales con sus múltiples variedades se hallan en un $28.20 \%$ de los casos, siendo el primero, con un $13.33 \%$, la metrorragia.

Anotamos que de un porcentaje de nulíparas del $23 \%$, solo se halla una esterilidad primaria. Falla en las historias? Falla en la anamnesis?

Que no se presenten sino un $8.71 \%$ de algomenorreas, nos hace hacer la misma pregunta!

\section{ETIOLOGIA}

La etiología y patogenia de la enfermedad pélvica inflamatoria, es bien conocida y no es necesario recalcar sobre este punto.

Al analizar las historias observamos que solo un $43 \%$ de las mismas presentan un estudio bacteriológico del flujo, que dis- 
minuye a un $20 \%$, si consideramos aquellos casos que por medio de cultivo se llegó a una etiología bacteriológica precisa.

Si bien es cierto que estos exámenes no dan siempre el agente causal, es conveniente buscarlos de manera sistemática para poder apreciar como lo hace Blinik (3), el hecho de que solo un $2 \%$ de gonococos fuercn aislados en las anexitis crónicas, de 216 pacientes en los hospitales de Harlem y Beth Israel, de Nueva York.

Este Cuadro demuestra que falta mayor estudio de la etiología, base indispensable para un tratamiento adecuado y bien dirigido.

Referente a la etiología tuberculosa hallamos un $5.10 \%$ de los casos contra un $2.3 \%$ en 1946 .

\section{CUADRO No 5}

ANTECEDENTES ENFERMEDAD ACTUAL

Aborto provocado

Raspado uterino

Aborto espontáneo

Parto

Maniobras instrumentales

(biopsias endometrio)

Ectópico

\begin{tabular}{rc} 
Casos & $\%$ \\
19 & $9.7 \%$ \\
19 & $9.7 \%$ \\
12 & $6.1 \%$ \\
5 & $2.56 \%$ \\
2 & $1.02 \%$ \\
1 & $0.51 \%$ \\
\hline 58 & $29.74 \%$
\end{tabular}

Dato sin consignar en la Historia

o imposible de verificar

$70.26 \%$

Mejor estudio histológico de las lesiones halladas en la cirugía, que entonces fue de un porcentaje de $4 \%$, y que hoy se practica en el $100 \%$ de los casos, es tal vez la causa del aumento de esta etiología en nuestro medio. Falta, sí, el estudio bacteriológico de todas las piezas quirúrgicas extirpadas. El porcentaje que presentan varios autores con relación a la tuberculosis genital oscila entre el 1 y el $8 \%$. $(4,5,6,7,8,9)$.

El mayor auge del estudio de la tuberculosis genital, se debe al conocimiento mayor del problema en la infertilidad matrimo- 
nial, en cuyo estudio se encuentran con mayor frecuencia lesiones tuberculosas de endometrio, insospechadas desde el punto de vista clínico. De ahí el interés que por esta entidad se ha despertado y que cada vez sea mayor el número de trabajos al respecto.

Solo 5 casos de gonococos aislados al cultivo con un porcentaje de $2.55 \%$, y un $57 \%$ sin dato en la historia, nos dice de la importancia del problema.

\section{ANTECEDENTES DE LA ENFERMEDAD ACTUAL}

En los antecedentes próximos de la entidad en estudio (Cuadro número cinco), el aborto provocado y los raspados uterinos llevan la primacía como causa directa.

El primer caso no merece comentario, y su importancia es bien conocida de todo ginecólogo.

El raspado, como causa inmediata, sí hace pensar en la falla médica de los centros que atienden estas pacientes. A ellos corremos traslado para que mejoren diagnósticos, técnica y asepsia ¿iuirúrgica.

Dos casos de biopsias de endometrio fueron de etiología instrumental de la inflamación pelviana, seguramente se olvidaron los preceptos de asepsia y demás datos a tener en cuenta para esta clase de exámenes especializados. El porcentaje sin embargo, es mínimo en relación con la entidad en estudio, y aún de menor significancia si consideramos el número de estas maniobras que se practican rutinariamente en los servicios de ginecología.

CUADRO No 6

FORMAS EVOLUTIVAS

Primer ataque (agudas)

Segunda o más (reagudizaciones)

Casos

$\%$

Sin dato

110

84

1

195
$56.4 \%$ $43.07 \%$ $0.51 \%$ 


\section{CUADRO No 7 \\ SINTOMAS INICIALES}

\begin{tabular}{|c|c|c|c|c|}
\hline \multirow{3}{*}{ Dolor abdominal } & \multirow[b]{2}{*}{ aislado } & & \multirow[t]{2}{*}{ Casos } & \multirow{3}{*}{$\begin{array}{c}\% \\
95.7 \% \\
95.7 \%\end{array}$} \\
\hline & & 28 & & \\
\hline & asociado & 159 & 187 & \\
\hline \multirow{2}{*}{\multicolumn{3}{|c|}{ Fiebre asociada a otros síntomas }} & 111 & $81.4 \%$ \\
\hline & & & & $23.07 \%$ \\
\hline \multirow{3}{*}{ Metrorragia } & aislada & 4 & \multirow{2}{*}{35} & \multirow{2}{*}{$21.27 \%$} \\
\hline & asociada & 31 & & \\
\hline & aislado & 1 & \multirow{2}{*}{31} & \multirow{2}{*}{$\begin{array}{l}15.8 \% \\
15.8 \%\end{array}$} \\
\hline \multirow{2}{*}{ Flujo genital } & asociado & 30 & & \\
\hline & aislada & 1 & \multirow[b]{2}{*}{18} & \multirow{2}{*}{$\begin{array}{ll}9.2 \% \\
9.2 \%\end{array}$} \\
\hline Tumefacción abdominal & asociada & 17 & & \\
\hline \multirow{3}{*}{$\begin{array}{l}\text { Diarrea asociada a otros } \\
\text { Disuria asociada a otros } \\
\text { Cefálea asociada a otros }\end{array}$} & sintomas & & 15 & \multirow{4}{*}{$\begin{array}{l}7.64 \% \\
4.61 \% \\
3.58 \% \\
2.5 \% \\
2.5 \%\end{array}$} \\
\hline & sintomas & & 9 & \\
\hline & $\begin{array}{l}\text { sintomas } \\
\text { aislada }\end{array}$ & 1 & 7 & \\
\hline Constipación & asociada & 4 & 5 & \\
\hline \multirow{2}{*}{\multicolumn{3}{|c|}{$\begin{array}{l}\text { Náusea asociada a otros síntomas } \\
\text { Disnea asociada a otros síntomas }\end{array}$}} & 2 & 1.02 \\
\hline \multirow{2}{*}{\multicolumn{3}{|c|}{ Meteorismo asociado a otros síntomas }} & 1 & $0.51^{c}$ \\
\hline & & & 1 & $0.51 \%$ \\
\hline \multicolumn{3}{|c|}{ Hipo asociado a otros síntomas } & 1 & $0.51 \%$ \\
\hline \multicolumn{3}{|c|}{ Calofrío asociado a otros síntomas } & 1 & 0.51 \\
\hline \multirow{2}{*}{\multicolumn{3}{|c|}{$\begin{array}{l}\text { Retención vesical asociada a otros síntomas } \\
\text { Tensión premenstrual asociada a otros síntomas }\end{array}$}} & 1 & $0.51 \%$ \\
\hline & & & 1 & $0.51 \%$ \\
\hline \multicolumn{3}{|c|}{ Ascitis asociada a otros síntomas } & 2 & $1.02 \%$ \\
\hline \multicolumn{3}{|l|}{ NO HAY DATO } & 2 & $1.02 \%$ \\
\hline
\end{tabular}

\section{CUADRO No 8 \\ EXAMEN GENITAL}

$\begin{array}{lccc} & \text { Si } & \text { Casos } & \\ & \text { no } & 133 & 68.2 \% \\ \text { Flujo genital } & \text { no dato en la Hria.? } & 54 & 4.08 \% \\ & \text { sin dato } & 27.6 \% \\ \text { Tumefacción parauterina } & 161 & 87.6 \% \\ \text { Cervicitis } & 45 & 23.07 \% \\ \text { Cáncer cervical } & 2 & 1.02 \% \\ \text { Colpocentesis } & \text { positiva 21 (77.7\%) } & & \\ & & 27 & 13.8 \%\end{array}$


Un $70 \%$ de fallas para averiguar esta causa inmediata en las historias, nos habla por sí solo de la importancia de mejorar nuestro historial clínico, pero creemos, basados en el conocimiento etiológico, que ese porcentaje comprende un solo síntoma: la menstruación, lo cual nos daría pauta para pensar que está un $10 \%$ por encima del promedio de las estadísticas sobre infección pelviana de tipo gonocócico. (4)

\section{FORMAS EVOLUTIVAS}

El Cuadro seis nos muestra la incidencia de las formas evolutivas, es decir, formas agudas y reagudizaciones de estados crónicos. Según él, existe un 56.4\% de formas agudas, en las cuales anteriormente no se habían presentado síntomas en las pacientes que hicieran acudir a la consulta. Ulteriormente, al comentar los resultados del examen genital, volveremos sobre este asunto.

\section{SINTOMAS INICIALES}

Referente a síntomas iniciales nuestra patología en nada se diterencia de lo comunmente aceptado al respecto (Cuadro número siete).

El meteorismo que revela parálisis intestinal no se presenta sino en un solo caso, dato curioso, pues este síntoma es mucho más fiecuente en todas las estadísticas sobre salpingitis; de ahí que la succión naso-gástrica sea uno de los tratamientos aconsejados en primera instancia para todas las pacientes. (13)

La ascitis fue debida a una peritonitis tuberculosa, que seguramente precedió a la tuberculosis anexial.

No hay dato en 2 casos, lo cual representa un $1.02 \%$ de falas en nuestras historias al respecto.

\section{EXAMEN GENITAL}

El Cuadro ocho nos muestra: $1^{\text {o }} 54$ casos en que no se consigna en la historia si había o no, flujo al examen pélvico, es decir, un $27.6 \%$ de las historias. Del resuitado de este examen se sacaron los porcentajes con relación a los síntomas ginecológicos que describimos anteriormente en los antecedentes de las pacientes. 
$2^{\text {o }}$ Tumefacción parauterina en 161 casos, con un 87.6\%. A este respecto y observando el Cuadro nos preguntamos si había en ellas salpingitis agudas, o si eran todas reagudizaciones de formas crónicas.

Creemos lo segundo, aun cuando el dato del primer ataque indica 110 casos De ahí que la anamnesis deba ser más cuidadosa aún para dilucidar este problema de gran trascendencia en el tratamiento a seguir en las pacientes.

$3^{\circ}$ Solo 45 casos de cervicitis en 195 pacientes, nos hace pensar en que falta consignar el examen ginecológico completo en muchas historias.

$4^{\text {O }}$ Finalmente solo se efectuó la colpocentesis en un $13.8 \%$ de los casos. Su positividad en un $77.7 \%$, es decir, en 21 de los 27 casos, nos dice de la importancia de tal método que a más de afirmar un diagnóstico nos es de gran utilidad para investigar el agente causal, practicar antibiogramas, datos fundamentales para hacer un buen tratamiento.

Bien es sabido que en los cultivos de colpocentesis, generalmente no se aprecian gérmenes (4). Sin embargo, se halla con frecuencia la Scherichia o el enterococo, gérmenes sensibles a la penicilina. Por otra parte, en ocasiones se aislan gérmenes $(3,14)$ que si no son los causales de la enfermedad, se presentan como responsables de infecciones secundarias que también debemos tener en cuenta para la terapia.

En nuestro estudio no se halló un solo cultivo de este tipo ni de las piezas quirúrgicas extirpadas.

\section{CUADRO No 9 \\ COMPLICACIONES}

Pelviperitonitis

Peritonitis generalizada

Fístula anexo parietal

Peritonitis T.B.C.

T.B.C. pulmonar

Enteritis T.B.C.

Hematoma intraligamentario

Bronconeumonía a estafilococo

$\begin{array}{cl}\text { Casos } & \\ 15 & 7.6 \% \\ 4 & 2.05 \% \\ 1 & 0.51 \% \\ 1 & 0.51 \% \\ 1 & 0.51 \% \\ 1 & 0.51 \% \\ 1 & 0.51 \% \\ 1 & 0.51 \%\end{array}$


Fístula intestinal

Intolerancia medicamentose

1

$0.51 \%$

Fístula vésico vaginal

Fístula urétero-vésico-vaginal

Absceso pelviano

Fístula coloparietal

Absceso subfrénico

1

$0.51 \%$

Coroiditis

\section{COMPLICACIONES}

Cuadro nueve. Como es lógico en estos casos, la principal complicación fue la pelviperitonitis con un $7.6 \%$, porcentaje muy bajo en relación con otras estadísticas, que muestran, como la de Collins y Janzen un $38.4 \%$ (13).

La peritonitis generalizada corresponde a rupturas de abscesos pélvicos o piosalpinx, dos de los cuales fueron los causantes de la mortalidad en este trabajo. Este porcentaje de por sí es bajo, si se compara con otras estadísticas, ya que en nuestro medio actualmente solo es de un $2.05 \%$. Sin embargo, la mortalidad de esta complicación, representa un $50 \%$ en nuestra experiencia actual, contra un $100 \%$ que hallábamos en 1946.

Otros autores consultados, Novak, Boissier, Robert, dan a la pelviperitonitis una frecuencia mayor, pero sin que den porcentajes al respecto. $(4,5,15)$.

Las demás complicaciones que representan en total 14 casos, o sea un $48 \%$ de las mismas, son casos aislados que no requieren comentario especial, salvo el caso de intolerancia a la butazolidina (fenil-butazona), que nos obliga a pensar en el bajo poder tóxico de esta droga usado a las dosis farmacodinámicas, y que algunas escuelas norteamericanas han querido exagerar en forma tal que casi proscriben el medicamento. 
CUADRO No 10

TRATAMIENTO MEDICO

Droga

Penicilina sola

con cirugía

Penicilina sola

Estreptomicina cirugía

Terramicina sola

con cirugía

Penicilina sola

Butazolidina cirugía

Terramicina sola

$\stackrel{+}{\text { Butazolidina con cirugía }}$

Penicilina sola

Sulfas $\stackrel{+}{ } \quad$ con cirugía

Butazolidina

Terramicina sola

Penicilina con cirugía

Sulfas

Penicilina + Butazolidina + diatermia

Tetraciclina + Sulfas + Butazolidina

Penicilina + Estreptomicina + Butazolidina 3

Penicilina con cirugía

19

24

9

9

5

7

5

3

6

2

3

7

$3.57 \%$

4

4

3

4

$\stackrel{+}{\text { Cloromicetina }}$

Cloromicetina + cirugía

Penicilina + tetraciclina i.v. + cirugía

$1.02 \%$

Terramicina + cloramfenicol + cirugía 2

$1.02 \%$

Penic. + Estrept. + Tetracicl. + Cirug. 2

$1.02 \%$

Penicilina sola

1

$1.02 \%$

Estreptomicina

Diatermia con cirugía 1

Penicilina + sulfa + terramicina

Terramicina + Clornf. + Penicilina 
Penicilina + Estrepto. + tetraciclina i.v. 1

$0.51 \%$

Tetracicl. + isocotinilhidraz. + Dihidroestreptomicina

Tetraciclina i.v. + oral

Tetraciclina + sulfas

Tetraciclina i.v. + sulfas

Isoniacida + Estreptomicina 1

Oxitetraciclina + sulfas

$0.51 \%$

Penicil. + Tetraciclina + butazolidina + Diater.

Penicilina + Prednisona

$0.51 \%$

Penicilina + Prednisona + cloranfenicol 1

$0.51 \%$

Tetraciclina i.v.

$0.51 \%$

Terramicina + cortisona

$0.51 \%$

$0.51 \%$

Penicilina + sulfas + butazolidina 1

$0.51 \%$

Penic. + Butaz. + Acromicina + Ditermia 1

$0.51 \%$

Penic. + Oxitetrac. + Butaz. + Diater. 1

$0.51 \%$

Penic. + Aureomic. + estrept. + diater.

$$
+ \text { prednisona }
$$

$0.51 \%$

Penic. + aureomicina + butazolidina 1

Oxitetracic. + diatermia + Butazolidina 1

$0.51 \%$

Oxitetraciclina + sulfa + diatermia 1

$0.51 \%$

Penic. + Oxitetra. + Butazol. + Ditermia 1

$0.51 \%$

Estrept. + Cloranfenicol + sulfas 1

$0.51 \%$

Penic. + Estrept. + Tetrac. + Butazol. 1

$0.51 \%$

Penicilina + sulfas + tetraciclina $\quad 1$

$0.51 \%$

Aureomicina

$0.51 \%$

Sulfadiazina + diatermia

Estrept. + Piem. + diatermia

$0.51 \%$

$0.51 \%$

Kananicina + Penic. + furandatina

$$
+ \text { Cirugía }
$$

Estrep. + Pas. + isoniacida + Cirug. 1

Terramicina + isoniacida + cirugía 1

Estrept. + Pas + cirugía 1

Tetrac. + Estrept. + Kanamicina + Cirug. 1

$0.51 \%$

$0.51 \%$

$0.51 \%$

$0.51 \%$

$0.51 \%$

Butazol. + oxitetraciclina + diater.

+ histerolin-denectomía

Butazol. + oxitetraciclina + cirugía

Sulfas + Butazol. + diater. + cirugía

Sulfas + Oxitetra. + Cloraf. + cirugía

$0.51 \%$

Penic. + tetraciclina + sulfas + cirugía 
Penicilina + Acrom. + Estrept. + cirugía 1

Penic. + Estrep. + Pas + cirugía

Penicilina + Oxitetra. + cirugía

Penic. + Cloranf. + Oxitetra. + sulfas

+ Butazol. + cirugía $110.51 \%$

Penic. + Oxitetra. + Estrept. + cirugía $1 \quad 0.51 \%$

Oxitetra. + Estrept. + Cloramf. + Iloticina

+ Prednis. + Cirugía 1

$0.51 \%$

Penicilina + Estrept. + sulfas + cirugía 1

$0.51 \%$

Tetrac. + Cloramf. + Estrep. + cirugía 1

$0.51 \%$

Estrep. + Piem. + Predr.

$0.51 \%$

Sulfas (un día)

$0.51 \%$

Oxitetraciclina

$0.51 \%$

Falta hoja de tratamiento o no se consignó $\quad 6$

$0.06 \%$

\section{TRATAMIENTO}

Cuadro diez. Ya hace años Meiggs (6) dijo: Todo caso que requiere cirugía es la confesión de falla en el ginecólogo. (16)

En el año de 1946 (2) nuestro porcentaje de tratamiento médico-quirúrgico era de $45.07 \%$ contra $47.2 \%$ en la actualidad. En el primer chequeo estadístico el tratamiento médico daba un $40.64 \%$, y actualmente presentamos un $52.2 \%$.

Si bien es cierto que el promedio estadístico da un $20 \%$ de cirugía para esta entidad, y que por lo tanto, no llega a colmar las aspiraciones de Meiggs, nuestro porcentaje dobla este tanto por ciento que presentan las estadísticas de otros países. Su comentario es obvio. (13)

El análisis cuidadoso de nuestros tratamientos nos pone de manifiesto dos hechos interesantes:

$1^{\text {O }}$ Cuando la antibioterapia está aislada sin otro método terapéutico, existe un porcentaje mayor de casos que van a la cirugía.

$2^{\text {o }}$ Cuando se combina con antiflogísticos, especialmente con la fenil-butazona, observamos que el porcentaje quirúrgico disminuye o aún desaparece por completo.

Se dirá que son casos menos severos, o que aquello fue coincidencia, pero lo cierto es que el herho, aun cuando la casuística 
no es de gran importancia, nos pone de manifiesto lo tantas veces anotado, de que los métodos antiflogísticos $(18,20)$ ya sean fisioterápicos como lo preconizaba Raab (16) en 1942 y con él las escuelas europeas, o con los actuales antiflogísticos del tipo de la fenil-butazona y de los corticoesteroides que día a día se han ido perfeccionando, mejoran el cuadro clínico, acortan la evolución del proceso y hacen disminuír el tratamiento quirúrgico. (13)

Ya hace quince años, uno de nosotros insinuaba un mayor tratamiento fisioterápico con el objeto de mejorar los resultados médicos de esta entidad. Qué decir hoy, si a ello agregamos las drogas antes mencionadas? Por otra parte la antibioterapia ha sido, según lo apreciamos en el Cuadro adjunto, dada de manera anárquica y sin una pauta preconcebida.

En todos los casos la penicilina debe ser el arma de choque inicial, y una vez aislado el germen ojalá con antibiograma (12, 13) cambiar sí o no por ctro antibiótico más adecuado para tal o cual caso.

En igual forma, y a la vez, se pueden usar combinados en el ataque agudo, los corticoides, la fenil-butazona, las ondas cortas, como la experiencia lo demuestra, pues si una sola de las drogas aumenta su eficacia, con mayor razón la combinación de varias medidas terapéuticas que se complementan.

Creemos que esta es la ruta que debemos seguir, para obtener dos objetivos principales:

a) Menor porcentaje de cirugía en la enfermedad inflamatoria pélvica.

b) Mejor porvenir ginecológico y aún obstétrico de estas pacientes en edad activa genital.

La indicación quirúrgica debe a su vez ser sometida a una pauta definida:

$1^{\circ} \mathrm{Si}$ el proceso agudo cede y la o las tumefacciones parautrinas van disminuyendo de volumen, la eritrosedimentación se hace normal, el tratamiento médico debe continuarse hasta tanto las lesiones permanezcan estacionarias y por lo tanto refractarias al mismo. Esta sería la pauta para cirugía, y con ello creo, disminuiría el porcentaje quirúrgico de manera considerable. 
$2^{\circ}$ En las reagudizaciones de procesos crónicos con tumefacciones preexistentes, el tratamiento debe ser más prolongado, y siempre acompañado de los métodos terapéuticos anteriormente anotados. Este medida, aconsejada por uno de nosotros hace unos años, se puso en práctica con buenos resultados, aun cuando no hay datos estadísticos, en los años de 1955 a 1959. Pero fue abandonada, pues en solo siete veces, con un porcentaje del $3.57 \%$ de los casos, se usó dicha terapia.

Finalmente, en lo tocante a antibióticos debemos recordar el sinergismo y antagonismo antibiótico para encausar la terapia, ya que este punto. como la duración del tratamiento y su concentración óptima, son bases fundamentales para toda terapéutica anti-infecciosa en nuestros tiempos. (22)

\section{CUADRO No 11}

\section{TRATAMIENTO QUIRURGICO}

Salpingooforectomía izquierda

Salpingooforectomía derecha

Salpingectomía izquierda ,endometrosis 1)

Histerectomía total + salpingooforectomía

bilateral miomatosis

Salpingectomía bilateral

Salpingectomía derecha (ectópico 1)

Salpingooforectomía bilateral

(quistes ser. ovar. 1)

Colpotomía

Raspado

Drenaje abdominal (endometrosis 1)

Histerectomía total + salpingectomía bilateral (miomatosis 1)

Histerectomía total con salpingooforectomía derecha (miomatosis 1)

Salpingectomía derecha y salpingooforectomía izquierda

Salpingectomía parcial + salpingoplastia bilateral (esterilidad 1)

Salpingoooforectomía D + salpingolisis izq. Histerolifadenectomía (Ca cervical + Salping.)

\section{Casos}

12

12

7

5

6

5

4

4

4

4

3

3

3

2

2

2
$\%$

$13.04 \%$

$13.04 \%$

$7.60 \%$

$5.43 \%$

$6.52 \%$

$5.43 \%$

$4.34 \%$

$4.34 \%$

$4.34 \%$

$4.34 \%$

$3.26 \%$

$3.26 \%$

$3.26 \%$

$2.17 \%$

$2.17 \%$

$2.17 \%$ 
Liberación de adherencias

Salpingectomía izquierda + salpingoooforectomía D

\section{2}

Miomectomías

Salpingoooforectomía izquierda + miomectomías

Punción de hidrosalpinx (?)

Persuflación tubaria (ideal)

Ooforectomía derecha (?)

Salpingoooforectomía D + salpingectomía

parc. izquierda

Salpingectomía izquierda + salpingoplastia der.

Colpotomía + salpingectomía izq. (ectópico)

Salpingectomía bilateral + ooforectomía izq.

Casos sin tratamiento quirúrgico
$2.17 \%$

$2.17 \%$

$1.08 \%$

$1.08 \%$

$1.08 \%$

$1.08 \%$

$1.08 \%$

$1.08 \%$

$1.08 \%$

$1.08 \%$

$1.08 \%$

$52.8 \%$

\section{TRATAMIENTO QUIRURGICO}

Cuadro once. En 1946, la salpingectomía ocupaba el primer lugar, dando un porcentaje del $33 \%$ contra un $6.52 \%$ en el momento actual, que ocupa el $5^{\circ}$ lugar en el tipo de terapia quirúrgica. Actualmente, practicando cirugía lo menos mutilante posible, la principal intervención fue la salpingoooforectomía unilateral en un porcentaje del $26.08 \%$ en total, o sea un $13.04 \%$ para cada anexo.

La "histerectomía pura" para proceso inflamatorio, solo se efectuó en 4 oportunidades, es decir, en un $4.34 \%$ de los casos. Antaño esa operación era mucho más frecuente en nuestro medio, $10.67 \%$.

No se practicó ni una sola vez la salpingectomía, que en 1946 proscribíamos como tratamiento inadecuado para esta entidad.

Se observa además en este Cuadro, mayor tendencia a las plastias tubarias, que antaño, no se intentaban.

Se sacó como dato quirúrgico una punción de hidrosalpinx (que en el Cuadro figura con un interrogante) y que fue ampliamente criticado a uno de los miembros del grupo ginecológico. No hay necesidad de más comentarios, sobre este caso.

Finalmente aparece en ese Cuadro estadístico una persuflación tubaria que no excluímos del mismo, pues aun cuando ello no es un tratamiento quirúrgico, sí es un procedimiento que de- 
be tenerse en cuenta para el criterio de curación. En algunos casos, puede emplearse como método el tratamiento acompañado de las hidrotubaciones, especialmente en aquellos casos en que existe esterilidad y se comprueba obstrucción a nivel del pabellón tubario, como secuela del proceso inflamatorio. $(17,23)$.

Para terminar el comentario al Cuadro del tratamiento quirúrgico, nuestra meta debe ser llegar con el tratamiento médico, a solo operar pequeñas secuelas obstructivas, bridas adherenciales sin practicar extirpación de ningún órgano.

\section{CUADRO No 12 \\ DURACION DE HOSPITALIZACION}

\begin{tabular}{|c|c|c|}
\hline Días & Casos & $\%$ \\
\hline 1 a 10 & 54 & $27.6 \%$ \\
\hline 10 a 20 & 46 & $23.58 \%$ \\
\hline 20 a 30 & 20 & $10.18 \%$ \\
\hline 30 a 40 & 19 & $9.67 \%$ \\
\hline 40 a 50 & 2 & $1.02 \%$ \\
\hline 50 a 60 & 1 & $0.51 \%$ \\
\hline 60 a 70 & 9 & $4.59 \%$ \\
\hline 70 a 80 & 2 & $1.02 \%$ \\
\hline 80 a 90 & - & \\
\hline 90 a 100 & 3 & $1.53 \%$ \\
\hline 100 a 110 & 1 & $0.51 \%$ \\
\hline 110 a 120 & 3 & $1.53 \%$ \\
\hline 120 a 130 & 4 & $2.04 \%$ \\
\hline 130 a 140 & - & 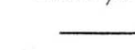 \\
\hline 140 a 150 & 4 & $2.04 \%$ \\
\hline 150 y más & 16 & $8.2 \%$ \\
\hline Sin dato & 5 & $2.55 \%$ \\
\hline
\end{tabular}

Promedio de permanencia hospitalaria: 18 días.

\section{DURACION DE LA HOSPITALIZACION}

Cuadro doce. Si en 1946 el promedio de hospitalización era de 45 días, en la actualidad es de 18 días.

Paradójicamente, en aquel entonces promulgábamos la fisioterapia para acortar el tiempo de permanencia hospitalaria. $\mathrm{Y}$ hoy 
creemos que se debe insistir más médicamente, antes de ir a intervenir quirúrgicamente.

Habrá casos en los cuales nuestro afán de hacer una buena asistencia y de mejorar la estadística por este aspecto, nos haga quizá apresurar el acto quirúrgico?

Por otra parte, debemos recordar y hacer comprender a las pacientes, que una vez enfriado el proceso y en vías de curación; su tratamiento ambulatorio en las consultas externas, es posible, sin recargar los servicios con permanencias exageradas, como los casos descritos de 150 días o más. Todo extremo es pernicioso y debe evitarse; el análisis crítico nos lleva a situarnos en el justo medio.

\section{CUADRO No 13 \\ EVOLUCION DE LA ENFERMEDAD}

$\begin{array}{lrr} & \text { Casos } & \% \\ \text { Curación } & 80 & 41.02 \% \\ \text { Mejoría } & 108 & 55.03 \% \\ \text { Salida voluntaria } & 3 & 1.53 \% \\ \text { Muerte } & 2 & 1.02 \% \\ \text { Sin dato } & 2 & 1.02 \%\end{array}$

EVOLUCION DE LA ENFERMEDAD

Cuadro trece. En el Cuadro trece observamos las causas de salida del servicio.

Curación clínica inmediata en un $41 \%$ de los casos, contra el $70 \%$ que hallábamos en 1946. Creo que hoy se es más justo al valorar la causa de salida, y por lo tanto, el porcentaje de curaciones es menor. Ya decíamos antaño que la curación no se podría afirmar sino viendo la evolución ulterior de los casos por un año o más. En nuestro medio, es casi imposible este control de la paciente.

Salieron por mejoría un $55.03 \%$; en 1946 , dábamos este rótulo al $6.95 \%$.

Salidas voluntarias del servicio, en un $1.53 \%$, contra un $13,35 \%$, años atrás. Esto indica una mejor colaboración de la pa- 
ciente, mejor educación ccn mayor comprensión de su estado de enfermedad, que debe tratarse hasta cuando lo indique el médico.

Dos casos de muerte, que nos apresuramos a catalogar de inevitable, pues fueron bien tratadas, pero lo avanzado de la peritonitis que presentaban, hizo infructuosos los tratamientos médico-quirúrgicos que se practicaron. Esta causa da un porcentaje del $1.02 \%$, contra un $5.34 \%$ que exhibíamos en 1946 . Indudablemente, hemos mejorado en nuestras conductas quirúrgicas, pries a este respecto e imputables al tratamiento quirúrgico en sí, tenemos un $0 . \%$, contra un $8.76 \%$ de años atrás.

\section{CUADRO N $\mathrm{N}^{\circ} 14$ \\ LABORATORIO CLINICO \\ Casos}

$\%$

A) LEUCOCITOSIS

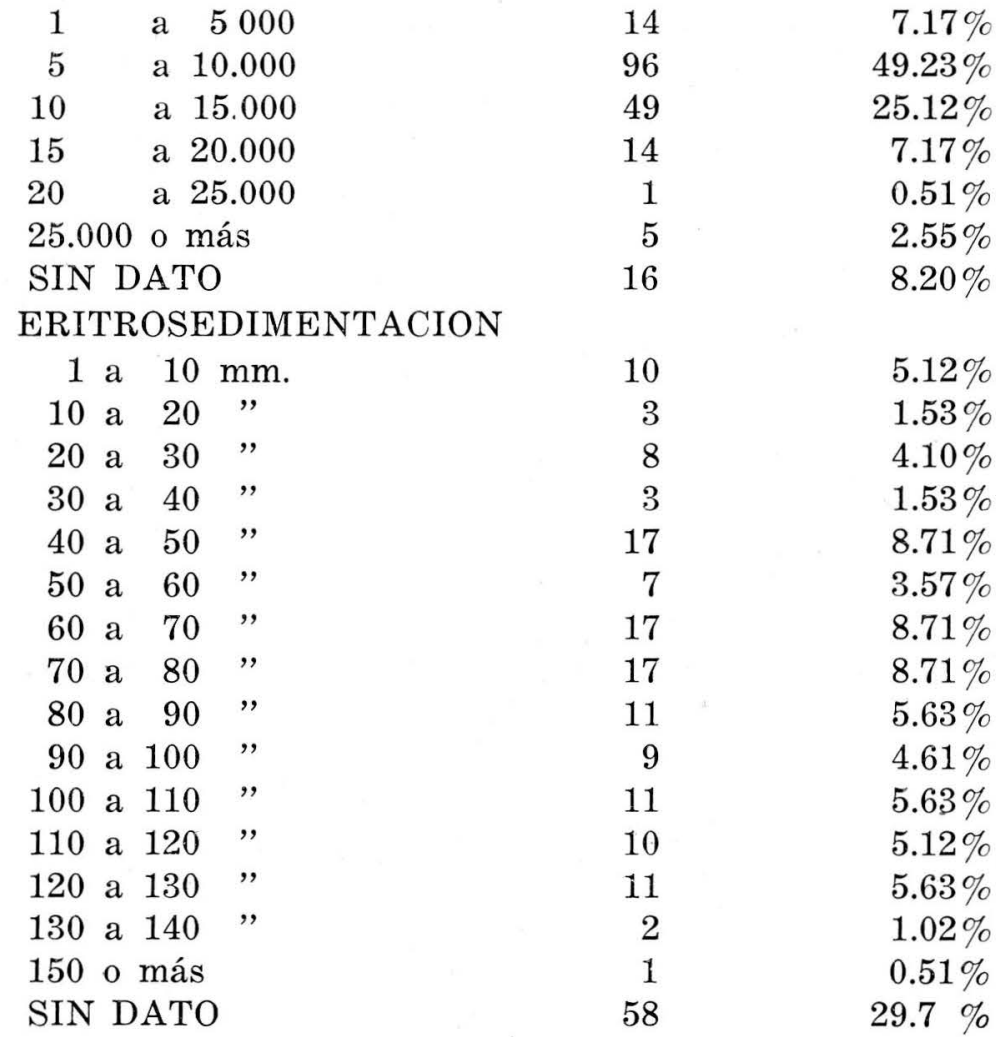




\section{LABORATORIO CLINICO}

Ei análisis del Cuadro catorce, no da lugar sino a un comentario de lo tantas veces anotado, que la eritrosedimentación es la más fiel ayuda de laboratorio para el diagnóstico de evolución, pronóstico e indicación de tratamiento quirúrgico, en caso de que sea necesario. Como a tal, siempre le debemos tener en mente, y recordar que muchos errores quirúrgicos del pasado se cometieron por abandonar la clínica y el laboratorio en el tratamiento de nuestras pacientes. (24)

Desafortunadamente no hallamos otros métodos de ayuda en el historial clínico estudiado para el diagnóstico etiológico de la entidad. Es así como no se practicaron cultivos de endometrio, inoculaciones al curí, ni test de la tuberculina en casos sospechosos de tuberculosis genital. $(14,23)$.

Por otra parte, el doctor Alberto Aparicio (27) halla en la CRP (proteína C reactiva), una ayuda valiosa para el diagnóstico, tratamiento y pronóstico de esta entidad, y al relacionarla con la eritrosedimentación. dice que es más fiel esta última.

\section{SUMARIO}

$1^{0}$ - Se presenta un estudio comparativo de 195 casos de enfermedad pélvica inflamatoria, con estadísticas en semejante período de tiempo en 1946, en el Hospital de San Juan de Dios de Bogotá, Cátedra de Ginecología.

$2^{9}-\mathrm{El}$ porcentaje actual con relación a las otras entidades ginecológicas del servicio, es de 10.07 en 21/2 años de estadística.

$3^{\circ}$ - La edad más frecuente en la mujer es de los 20 a los 40 años, con porcentaje del $76.85 \%$ sobre las otras edades.

$4^{0}$ - La entidad más frecuente en las pacientes primi o multíparas, con un $76 \%$ que cn las nulíparas.

$5^{\circ}$ - El flujo genital es el síntoma más frecuente con $68.20 \%$ de los casos; los trastornos menstruales se presentan en un $28 \%$ y la algomenorrea en un $8.71 \%$. La esterilidad conyugal se comprobó en solo $1.53 \%$ de los casos en este estudio.

$6^{\circ}$ - La etiología tuberculosa nos da un $5.10 \%$ contra un $2.3 \%$ en 1946. Apreciada clínicamente la etiología y por 
la localización en las piezas quirúrgicas, se halla un porcentaje de $34.7 \%$ para la etiología gonocócica, y un $44.5 \%$ para la infección séptica.

$7^{\circ}$ - Las formas agudas se presentaron en un $56.4 \%$; las crónicas en un $43.07 \%$. No hay dato en un $0.51 \%$.

$8^{\circ}-\mathrm{El}$ dolor fue el síntoma principal en un $95.7 \%$; la fiebre en un $81.4 \%$; el vómito en un $23 \%$; la metrorragia en un $21.27 \%$; el flujo genital en un $15.8 \%$; la tumefacción abdominal en un $9.2 \%$ de los casos, y la diarrea en el $7.6 \%$. Otros síntomas carecen de importancia clínica.

$9^{\circ}$ - La tumefacción parauterina es el signo más frecuentemente hallado: $87.6 \%$; el flujo genital, $68.2 \%$; cervicitis en un $23.07 \%$. La colpocentesis se practicó en un $13.8 \%$.

Existen grandes fallas en el historial clínico al respecto.

$10^{\circ}$ - La principal complicación fue la pelviperitonitis, con un $7.6 \%$; la peritonitis generalizada con $2.05 \%$. Las demás complicaciones carecen de importancia estadística.

$11^{\circ}$ - Se practicó tratamiento médico únicamente en 103 pacientes, o sea en un $52.2 \%$. Tratamiento médico quirúrgico en 92 casos, con $47.02 \%$.

$12^{\circ}$ - El tiempo promedio de permanencia hospitalaria fue de 18 días.

$13^{\circ}-\mathrm{El} 41.02 \%$ de İos casos evolucionó a la curación. Hubo mejoría en un $55 \%$, y defunción en un $1.02 \%$.

$14^{\circ}$ - La eritrosedimentación es el dato de laboratorio más importante en el diagnóstico de esta entidad.

\section{CONCLUSIONES}

$\mathrm{Al}$ analizar el trabajo surgen las siguientes conclusiones, que se derivan del análisis de la estadística comparada:

$1^{\circ}$ - La enfermedad inflamatoria pélvica no ha disminuído en nuestro medio de manera apreciable, como se esperaba con la aparición de los antibióticos. Urge mayor educación de nuestro pueblo en lo referente a higiene sexual, atención médica adecuada y centros de consulta en la provincia, de carácter oficial, pues 
creemos que un buen número de pacientes no tienen la asistencia médica adecuada para evitar estas infecciones. Nuestras estadísticas están a la par con las extranjeras por este concepto.

$2^{\circ}-$ Nuestras historias son aún deficientes, y es necesario mayor atención del personal de internos y residentes para mejorar la calidad de las mismas, no dejando de anotar en ellas los datos que son preciosos para evaluaciones ulteriores.

$3^{\circ}$ - Es necesario en todo caso de enfermedad pélvica inflamatoria llegar a un diagnóstico lo más exacto posible, y para ello recomendamos, la práctica rutinaria de cultivos, tanto de endometrio como de los líquidos de la colpocentesis, flujos, etc. Cuando se opera al igual que el examen patológico, debe hacerse el estudio bacteriológico de las piezas extirpadas.

Al respecto se debe estudiar el valor diagnóstico y pronóstico de la CRP en nuestro medio.

$4^{o}$ - Las complicaciones representan un porcentaje más bajo que el hallado en otros países.

$5^{0}-$ El tratamiento debe ser conducido según prácticas rutinarias del servicio. Ante todo se debe insistir en forma sistemática en el tratamiento médico, con las medidas terapéuticas hoy conocidas, tanto antibióticas como fisioterápicas, hormonales y quimioterápicas que bien conducidas mejorarán el porvenir ginecológico y obstétrico de estas pacientes. Solo en última instancia se debe recurrir a la cirugía bajo normas y pautas definidas.

Esperamos con ello lograr algún día la meta deseada a este respecto: no operar o hacerlo sobre secuelas sin extirpación de órganos.

$6^{\circ}$ - Debe existir mayor coordinación asistencial en los tratumientos de estas pacientes. No debemos olvidar que los tratamientos ambulatorios pueden, en muchos casos, evitar cirugías nuutilantes y mejorar en el peor de los casos, el porvenir le las pacientes.

$7^{\circ}$ - Nuestra estadística de mortalidad es baja, comparada con las extranjeras, y con las que exhibíamos hace quince años, vrobando por lo tanto que hemos mejorado a este respecto en los últimos años. 


\section{BIBLIOGRAFIA}

(1) AMAYA LEON HERNANDO Comentarios a un año de internado. Tesis. 1944.

(2) ESPINOSA Y ESPINOSA ALVARO. Anexitis. Comentarios a tres años de estadística en el servicio de ginecología del Hospital de San Juan de Dios. Tesis. 1946.

(3) BLINICK GEORGE. Gonorreal Disease in the females. Clin. Obs. and Ginecc. $2-2-492$. 1959 .

(4) E. NOVAK and E. NOVAK. Test Book Ginecology. 23-375. 1953.

(5) ROBERT BOISSIE. Ginecology and obst. 58-138, abril de 1959.

(6) HAINES MAGNUS. Tuberculosis salpingitys as seen by the pathologist and the surgeon. Am. J. Obst. and Ginec. 75, 3, 472. 1958.

(7) POSNER CHARLES. ROBIN LEO. A sucesful pregnancy after endometrial TBC Am. J. Obst. and Ginecc. 74, 5, 1.136. 1957.

(8) CRUZ AMAYA ARISTOBULO. Dos casos de piosalpinx tuberculoso. RV. Col. Obst. Y Ginec. 11, 5, 596. 1960.

(9) CHAVALIER RAUL. y SANMARTINO R. Permeabilidad tubaria y TBC. Obst. y Ginec. Lat. Am. 9, 450. 1951.

(10) HALBRECHT I. Healed Genita! Tuberculosis. Obst. and Ginec. 10. 73.1957.

(11) BALBRECHT I. Tuberculosis genital. Ginecc. Rat. 9. 419. 1958. (Y. B.).

(12) SCHAFER GEORGE. Antimicrcbial treatment of tuberculos salpingitis. Am. J. Obst. and Ginecc. 77, 9961959.

(13) COLLINS CONRAD G., JANSEN FREDERIC. Treatment of the pelvic absces. Cli. Obst. and Ginecc. 512, junio 1959.

(14) HALBRECHT I. The relative value of culture and endometrial biopsy in the diagnosis of genital tuberculosis. Am. J. Obst. and Ginecc. 75, 899, 1958.

(15) MEIGGS and STURGIS. Pregress in Ginecology. 2, 402, 1950 .

(16) RAAB ERNST. Las ondas corłas en ginecología. Ed. Pegaso, Madrid 1942.

(17) ASCENSO CABELL.O JORGE. HOYLE JAVIER. DE LA FUENTE RAFAEL. 450 hidrotubaciones histero-tubáricas realizadas en el Centro Peruano de Fertilidad Matrimonial. Rev. Col. Cbst. y Ginec. 10, 4, 260. 1959.

(18) AMOROCHO CARREÑO JORGE. Nuevas anotaciones sobre el uso de la fenil-butazona en las obstrucciones tubarias. Rv. Col. de Gin. y Obst. 11, 3, 413. 1960.

(19) AMOROCHO CARREÑO JORGE. Tratamiento de las afecciones anexoparametriales con la fenil-butazona. Memorias $2^{\text {a }}$ Conv. Col. de Obst. y Ginec. 315, 321. 1955.

(20) AMAYA LEON HERNANDO. Cortisona en el tratamiento de la obstrucción tubaria. Rev. Col. de Obst. y Gir., 9, 6, 569, 1958.

(21) RODRIGUEZ HERNANDO. La inoculación de secreción menstrual al cobayo en el diagnóstico de la TBC genital. Rev.C ol. de Obst. y Gin. 10, 2, 152. 1959.

(22) DOUGLAS GORDON, BIR N. BAUM STANLEY. The role of antibiotic in genital infections. Cl. Obst. and Ginec. 2, 413, 1959.

(23) RUEDA GONZALEZ RICARDO. Valoración de los métodos de exploración de la función tubaria. Rev. Col. Obst. and Ginec. VIII, 3, 115, 1957.

(24) CHATTAS ALBERTO. Eritrosedimentación. Su aplicación a la clínica. Salvat Editores. Buenos Aires, 1943.

(25) WERNER STEIMBERG. Histerosalpingography with ethiol. Am. J. Obst. and Ginec. 74, 11, 140. 1958.

(26) KARTER E. RUMMO B. P. Surgical Bludign Tendencies of pacients with cronic pelvic inflamatory disease. Am. J. Obst. and Gin. 75, 5, 1.100. 1957.

(27) APARICIO RUEDA ALBERTO. La CRP (C reaccio-protein) como auxiliar en el diagnóstico de apendicopatías e infecciones anexiales. Rev. Col. de Obst. y Ginec. Tesis. VIII-6-377, 1957. 


\title{
Terramicina en la Cavidad Abdominal
}

\author{
Dr. Alberto Zabaleta Lombana - Dr. Jorge Milanés*
}

Desde el pasado mes de Febrero hasta Junio del presente año, hemos verificado cincuenta observaciones en la Clínica Universitaria "Rafael Calvo C." sobre el uso del Clorhidrato de Oxitetraciclina, $(\mathrm{xx})$ en el acto operatorio de pacientes internadas en dicho servicio.

En general, con la llegada de los antibióticos se aprovechó su poder anti-infeccioso en el tratamiento de la peritonitis mediante su instilación en la cavidad abdominal. En 1955, entre nosotros, Alfonso Bonilla Naar (1) al cerrar el abdomen en las peritonitis generalizadas, dejaba una solución de Penicilina un millón de unidades y un gramo de Estreptomicina en 40 c.c. de agua destilada; además, drenes y otro antibiótico de amplio espectro por vía parenteral.

En 1956 William E. Schattenn (2) publicó sus observaciones sobre 38 casos de peritonitis generalizada mediante el uso de antibióticos intraperitoneal; de los cuales 20 lo fueron con Terramicina.

Para el efecto, una vez intervenido el paciente dejaba dos drenes, uno en la región subhepática derecha y otro a través del Douglas, mediante los cuales instilaba la solución antibiótica. Igual sistema de administración utilizaron A. Bonilla Naar, Alvarez Vásquez (1) en trabajo publicado en 196乞.

Experimentalmente se ha demostrado por observaciones sobre animales (2) (1) que los antibióticos en solución dejados en la cavidad abdominal no son tóxicos ni favorecen la aparición de adherencias.

Su administración en perros no anestesiados provoca la sensación de dolor cuando la concentración del producto es superior a los $2 \mathrm{mgm}$. por c.c. de solución. (2)

* Del "Departamento de Obstetricia" Universidad de Cartagena. 
Tal inconveniente no se presenta en los pacientes anestesiados o agregando a la solución antibiótica $2 \mathrm{mg}$. de ácido ascórbico por centímetro cúbico. (4)

METODO. - Preparamos una solución de Terramicina, tipo endovenoso; $250 \mathrm{mgm}$. en 15 c.c. de Dextrosa al $5 \%$ en agua destilada; para dejar en la cavidad peritoneal una vez verificada la intervención propuesta. En los casos considerados de pronóstico más grave utilizamos $500 \mathrm{mgm}$. de Terramicina en 20 c.c. de solvente. Al finalizar este trabajo nos servimos del suero fisiológico como solvente en cantidad de 30 centímetros.

Por lo demás, la Terramicina así preparada es la única medicación antibiótica que se administra; consignando expresamente en las órdenes médicas no aplicar ninguna otra droga de tal naturaleza en los días siguientes. Se continúan sí las medidas apropiadas de acuerdo con el estado y requerimiento del paciente: transfusiones, soluciones electrolíticas, calmantes de dolor etc. De igual manera, se toman todos los cuidados que son de rutina en el preoperatorio en la medida que la urgencia lo permita.

Este uso de la Terramicina en la cavidad abdominal prácticamente se ha hecho de rutina en la clientela quirúrgica del Servicio tanto civil como pensionada; habiéndose acortado con tal proceder su hospitalización. El estado general del paciente es mucho más satisfactorio: facies despejada, descenso marcado de la temperatura en las que han sido operadas en período febril, menor dolor a nivel de la herida; morbilidad postoperatoria reducida al mínimo, todo lo cual permite levantarlas con la confianza del enfermo, en las primeras 24 horas; y con las ventajas innegables de la movilización precoz.

En los casos observados no se ha presentado intolerancia de tipo alérgico ni síntoma abdominal alguno que interfiriera el postoperatorio.

Las intervenciones se verificaron mediante la raquianestesia; excepto en dos pacientes en las que debido a su mal estado general se recurrió a la anestesia local con Xilocaína.

La primera no toleró la solución; reaccionando con síntomas de lipotimia, sudoración, taquicardia; por lo que no llegó a inyectarse toda la cantidad (Historia: C. B. H.) ; y en la segunda, a pesar del trastorno acusado, se dejó toda la solución, terminán- 
dose de cerrar los planos. Esta sintomatología, no obstante lo inconveniente e inesperada, no tuvo mayores consecuencias, pasando en algunos minutos.

El tipo de anestesia usado, el solvente: agua destilada y la alta concentración de Terramicina pudieran provocar este malestar al entrar en contacto con los tejidos lesionados. Por ello, en las últimas pacientes cambiamos al suero fisiológico en cantidad de 30 centímetros.

De esta manera, completamos 50 tratamientos cuyo estudio resumimos en las historias y cuadros que acompañan este trabajo.

Para efecto de las anotaciones, consideramos la hora en que termina la intervención como comienzo del postoperatorio; y las 8 de la mañana del día de salida (hora en que generalmente se pasa la visita reglamentaria) como la de su término hospitalario.

Solamente dos de estos 50 casos, ambos operados en los mismos días y vecinos de cama, presentaron complicación bronconeumónica, lo que obligó al uso de antibióticos parenteral, dominándose rápidamente el cuadro. (Historias Nos. 02305 y 02106 que figuran con más detalles en los apartados siguientes).

Hemos incluído la Historia N⿳0 01684, paciente que no fue operada; y atendida con el diagnóstico de pelviperitonitis aguda. Previa punción del Douglas con extracción de aproximadamente 1 c.c. de líquido seropurulento, se inyectó por la misma vía los 15 c.c. de solución de Terramicina en Dextrosa al 5\% en agua destilada con resultados realmente notables.

Esta paciente acusaba dolor intolerable en el bajo vientre que dificultaba la exploración, tem. de 39.5; y además blefaritis bilateral. Antes de las primeras 24 horas había desaparecido toda sintomatología; incluso la blefaritis, dándosele de alta al siguiente día completamente bien.

No hemos hecho selección alguna de los casos para tratamiento, siendo tan solo desechados aquellos que por cualquier causa recibieran antibióticos antes de ser intervenidos. Las operaciones fueron llevadas a cabo por los profesores y jefes de Clínica, cinco en total; muchas de ellas con el carácter de urgente, vale decir, sin tiempo para una buena preparación preoperatoria.

Historiamos estas 50 observaciones en tres cuadros: Cesáreas Segmentarias Transperitoneales, Embarazos Ectópicos Rotos y Hematosalpinx. Con el título de "Varios" encuadramos los 
CUADRO No 1

\section{Cesáreas segmentarias transperitoneales}

\begin{tabular}{|c|c|c|c|c|c|c|c|}
\hline \multirow{2}{*}{ HIST. No } & \multirow{2}{*}{ CAUSA } & \multirow{2}{*}{$\begin{array}{l}\text { T. de P. } \\
\text { HORAS }\end{array}$} & \multicolumn{4}{|c|}{ POST. OPERAT. Mx. TEMPERAT. } & \multirow{2}{*}{ OBSERVACIONES } \\
\hline & & & DIAS & HORAS & GRADO & HORAS & \\
\hline 02479 & Cesárea Anterior & 0 & 1 & 20 & 37.6 & 28 & $\begin{array}{l}\text { G.2. - P.O. } 33 \text { años. Cesárea anterior por preclampsia hace } 18 \\
\text { meses. Está en tratamiento con hipotensores. }\end{array}$ \\
\hline 02337 & Sit. Transversa & 28 & 3 & 2 & 38 & 24 & G3. - P.2. - A las 48 horas de operada solicitaba su salida. \\
\hline 02106 & $\begin{array}{l}\text { Oclusión Vaginal } \\
1 / 3 \text { superior }\end{array}$ & $\begin{array}{l}\text { más } \\
10\end{array}$ & 5 & 20 & 38.8 & 52 & $\begin{array}{l}\text { Hrimigrávida, } 18 \text { años. A las } 48 \text { horas acusa dolor torácico, esca- } \\
\text { lofríos, fiebre, estertores cripitantes ambos pulmones. Bronconeu- } \\
\text { monía. Leucccitos } 18.550 \text {. Hematíes: } 2.480 .000 \text {. Hb: } 50 \% \text {. Se } \\
\text { utilizó antibiótico parenteral. }\end{array}$ \\
\hline 02305 & PI. Previa Cent. & 0 & 5 & 4 & 39.8 & 36 & $\begin{array}{l}\text { G.9. P 5-A } 331 \text { años. Malas condiciones nutricional y dentaria. } \\
\text { Pesó } 46 \mathrm{kl} \text {. Talla } 1.60 \text {. Entró a cirugía con } 38.3 \text { temp. Hizo bron- } \\
\text { coneumonía. Vecina de cama de la anterior. Se usó antibiótico } \\
\text { en el postoperatorio. Hematíes: } 2.910 .000 \text {. Hb. } 55 \% \text {. }\end{array}$ \\
\hline 02186 & $\begin{array}{l}\text { Procidencia } \\
\text { de cordón }\end{array}$ & $\begin{array}{l}\text { más } \\
10\end{array}$ & 4 & 13 & 38.4 & 45 & $\begin{array}{l}\text { G.12 P.9 A.2 } 38 \text { años. Hidrohematorrea } 3 \text { días antes de ingreso. } \\
2.580 .000 \text { hematíes. } 50 \% \text { de hemoglobina. Leucocitos: } 18.200 \text {. }\end{array}$ \\
\hline 01914 & $\begin{array}{l}\text { T. de P. } \\
\text { prolongado }\end{array}$ & 50 & 4 & 16 & 37.8 & 24 & $\begin{array}{l}\text { F'rimigrávida } 16 \text { años. Llegó con bolsa rota, considerable edema } \\
\text { de la vulva, meconio fétido. Atendida por comadrona. Temperatu- } \\
\text { ra } 37.5^{\circ} \text {. }\end{array}$ \\
\hline 09197 & Proc. de cordón & 9 & 3 & 2 & 37.5 & 36 & G.9 P.7 A 1 - 32 años. Hizo la procidencia en el servicio. \\
\hline 02184 & $\begin{array}{l}\text { T. de P. prolonga- } \\
\text { do. Suf. fetal }\end{array}$ & 27 & 3 & 7 & 37.6 & 60 & $\begin{array}{l}\text { G.2 P.1 } 18 \text { años. Embarazo gemelar no diagnosticado. Hematíes: } \\
3.140 .000 \text {. Hemog.: } 60 \% \text {. Leucocitos: } 20.600 \text {. }\end{array}$ \\
\hline 02844 & PI. Previa Cent. & 0 & 3 & 17 & 37.7 & 13 & G.12 P.5 A.6 34 años. Hematíes: 3.990.000. Hemoglb.: $75 \%$. \\
\hline 03217 & Primg. Añosa & 9 & 1 & 12 & 37.3 & 16 & Primigrávida. 35 años. Paciente pensionada. \\
\hline A.T.Ch & $\begin{array}{l}\text { Cesáreas Anteriores } \\
\text { por estenosis pélvica }\end{array}$ & - & 2 & 0 & 37.5 & 30 & $\begin{array}{l}\text { G.3 P.0 - } 25 \text { años. Dos embarazos anteriores terminados por cesá- } \\
\text { reas. Feto sexo femenino. } 3.450 \mathrm{grm} \text {. Talla } 49 \mathrm{~cm} \text {. Terramicina } \\
\text { en solución tisiológica: } 15 \text { c.c. }\end{array}$ \\
\hline
\end{tabular}


CUADRO N: 1

\section{Cesáreas segmentarias transperitoneales}

\begin{tabular}{|c|c|c|c|c|c|c|c|}
\hline \multirow{2}{*}{ HIST. No } & \multirow{2}{*}{ CAUSA } & \multirow{2}{*}{$\begin{array}{l}\text { T. de P. } \\
\text { HORAS }\end{array}$} & \multicolumn{4}{|c|}{ POST. OPERAT. MX. TEMPERAT. } & \multirow[b]{2}{*}{ OBSERVACIONES } \\
\hline & & & DIAS & HORAS & GRADO & HORAS & \\
\hline 02629 & $\begin{array}{l}\text { Cesárea corporal } \\
\text { ant. Preruptura } \\
\text { uterina }\end{array}$ & 6 & 2 & 0 & 38.5 & 30 & $\begin{array}{l}\text { G.2 P.0 - } 24 \text { años. Primer embarazo: cesárea corporal y peritoni- } \\
\text { tis. } 11 \text { meses más tarde, segundo embarazo. Hay dehiscencia de } \\
\text { rectos y hernia. Kahn positivo. Hematocrito } 34 \% \text {. Hemog.: } 60 \% \\
\text { Adherencias epiploicas. Hematoma a nivel de la cicatriz uterina a } \\
\text { punto de romperse. Se elimina la antigua cicatriz después de cesá- } \\
\text { rea segmentaria. Feto eritroblastósico. }\end{array}$ \\
\hline E. C. & PI. Previa Cent. & 3 & 2 & 0 & 37.5 & 30 & $\begin{array}{l}\text { G.2 P.1 - } 22 \text { años. Tres días antes, sangre abundante. En el ser- } \\
\text { vicio: palidez, angustia marcadas. Algunos vómitos. T.A.: } 80 \text { x } \\
50 \text {, pulso 120. Se transfunde } 500 \text { c.c. de sangre. Se interviene. } \\
\text { Al segundo día: } 2.490 .000 \text { hematíes. } 22 \% \text { hematocrito. } 40 \% \text { he- } \\
\text { mogl. Terramicina en sol. fisiológica. }\end{array}$ \\
\hline 02248 & $\begin{array}{l}\text { Pl. Previa. } \\
\text { Sit. Transversa }\end{array}$ & 0 & 1 & 20 & 37.2 & 28 & $\begin{array}{l}\text { Edad } 39 \text { años. Llegó al servicio por hemorragia vaginal indolora. } \\
\text { Embarazo a término. Situación fetal transversa. Bolsa intacta. }\end{array}$ \\
\hline I.C.C. & Cesárea Anterior & 4 & 1 & 21 & 37.8 & 9 & $\begin{array}{l}\text { G.8 P.6 Ultimo embarazo: cesárea por placenta previa. Esta vez } \\
\text { se interviene por la cesárea anterior. Edad } 34 \text { años. Buen estado } \\
\text { general. Bolsa intacta. Feto femn. } 4.100 \mathrm{gr} \text {. Talla } 50 \mathrm{cms} \text {. }\end{array}$ \\
\hline P.E.R. & PI. Previa & 0 & 1 & 20 & 37.5 & 28 & $\begin{array}{l}\text { G.8 P.7 - } 32 \text { años. Bolsa intacta. Buen estado general. } 32 \text { sema- } \\
\text { nas de embarazo aproximadamente. }\end{array}$ \\
\hline M.C.M. & $\begin{array}{l}\text { Sit. Fetal Transversa } \\
\text { Suf. Fetal }\end{array}$ & 32 & 2 & 10 & 38 & - & $\begin{array}{l}\text { G.11 P.10. L'egó al servicio después de } 29 \text { horas de t. de parto. } \\
\text { Bolsa intacta. Se rompe. El interno reconoce la posición anóma- } \\
\text { la. Tres horas más tarde cirugía. Feto: } 3.300 \text { gr. Pérdida regu- } \\
\text { lar de sangre. Se transfundieron } 500 \text { c.c. Entró a cirugía con } \\
38 \text { grados de temperatura. que cayó a partir de las } 40 \text { horas. } \\
\text { Estado catarral con expectoración. Se dejó terramicina: } 250 \text { mmg. } \\
\text { en } 30 \text { c.c. de sol. fisiológica. }\end{array}$ \\
\hline
\end{tabular}


CUADRO N: 1

\section{Cesáreas segmeniarias transperitoneales}

\begin{tabular}{|c|c|c|c|c|c|c|c|}
\hline \multirow{2}{*}{ HIST. N No } & \multirow[b]{2}{*}{ CAUSA } & \multirow{2}{*}{$\begin{array}{l}\text { T. de P. } \\
\text { HORAS }\end{array}$} & \multicolumn{4}{|c|}{ POST. OPERAT. Mx. TEMPERAT. } & \multirow[b]{2}{*}{ OBSERVACIONES } \\
\hline & & & DIAS & HORAS & GRADO & HORAS & \\
\hline 3.497 & $\begin{array}{l}\text { T. de P. prolong. } \\
\text { Present. de cara }\end{array}$ & 31 & 3 & 10 & - & - & $\begin{array}{l}\text { G.3 P.2 - } 34 \text { años. Bolsa rota. Hipersistolia. Entra a cirugía con } \\
38^{\circ} \text { de temperatura. Descendió a las } 48 \text { horas. }\end{array}$ \\
\hline 3.585 & $\begin{array}{l}\text { Desprendimiento pre- } \\
\text { maturo placenta } \\
\text { normoinserta }\end{array}$ & - & 5 & 18 & 39.4 & 48 & $\begin{array}{l}\text { G.5 P.3 A.1 } 27 \text { años. Prueba de t. de parto durante } 4 \text { horas in- } \\
\text { ducido. Se intervino por hemorragia. } 28 \text { semanas aproximadamen- } \\
\text { te de embarazo. Estado catarral. Postoperatorio: estertores crepi- } \\
\text { tantes pulmonares. Se usó Penicilina parenteral. Hematíes: } \\
3.990 .000 \text {. Hemog.: } 35 \% \text {. Hematocr.: } 18 \% \text {. Leucocitos: } 13.800 \text {. }\end{array}$ \\
\hline 3.644 & $\begin{array}{l}\text { Cesárea anterior por } \\
\text { PI. previa }\end{array}$ & 3 & 3 & 18.5 & 37.8 & 60 & $\begin{array}{l}\text { G.3 P.0 A.1 Primer embarazo: placenta previa y cesárea. A los } \\
4 \text { meses: nuevo embarazo y aborto. Estado catarral. Eventración } \\
\text { a nivel de la cicatriz laparotómica. Numerosas adherencias epi- } \\
\text { ploicas. Raquianestesia que termina con aplicación de pentotal. } \\
\text { Espasmo larírigeo y mal estado general de la paciente. }\end{array}$ \\
\hline J.N.A. & $\begin{array}{l}\text { T. de P. } \\
\text { prolongado } \\
\text { Preeclampsia } \\
\text { severa }\end{array}$ & 30 & 3 & 0 & 37.8 & 60 & $\begin{array}{l}\text { Primigrávida } 23 \text { años. T.A. } 195 \times 130 \text {. Pulso } 120 \text {. Temp.: } 38.4^{\circ} \text {. } \\
\text { Bolsa rota } 4 \text { horas antes. Anotados } 10 \text { tactos vaginales. Se utili- } \\
\text { zó hipotensores. Anestesia local con Xilocána. La solución de Te- } \\
\text { rramicina prcvocó lipotimia que duró algunos minutos. Al salir } \\
\text { de cirugía: T.A.: } 90 \times 50 \text {. Pulso } 132 \text {. A las } 12 \text { horas tempera- } \\
\text { tura } 36.6^{\circ} \text {. }\end{array}$ \\
\hline $\begin{array}{l}\text { E. P. } \\
\text { de T. }\end{array}$ & T. de P. prolongado & 31 & 1 & 21 & 37.4 & 24 & $\begin{array}{l}\text { Primigrávida pensionada. } 29 \text { años. Más de } 24 \text { horas con bolsa ro- } \\
\text { ta. Se anotan } 5 \text { exámenes vaginales para control de trabajo. Se } \\
\text { usó la Terramicina en solución fisiológica } 15 \text { c.c. }\end{array}$ \\
\hline L.C.C. & $\begin{array}{l}\text { T. de P. prolongado } \\
\text { Pres.: de Cara }\end{array}$ & 32 & 8 & 21 & 38 & 24 & $\begin{array}{l}\text { G.6 P.5 - Entró a cirugía con temperatura } 38.3^{\circ} \text { Extracción fetal } \\
\text { bastante laboriosa. A las } 48 \text { horas nueva elevación térmica que } \\
\text { coincide con congestión mamaria pcr bajada de la leche. Terra- } \\
\text { micina en suero fisiológico } 15 \text { c.c. }\end{array}$ \\
\hline
\end{tabular}


CUADRO N: 2

\section{Embarazos ectópicos rotos. - Hematosalpinx}

\begin{tabular}{|c|c|c|c|c|c|c|}
\hline \multirow[b]{2}{*}{ HIST. Ne } & \multirow[b]{2}{*}{ INTERVENCIONES } & \multicolumn{4}{|c|}{ POST. OPERAT. MX. TEMPERAT. } & \multirow[b]{2}{*}{ OBSERVACIONES } \\
\hline & & DIAS & HORAS & GRADO & HORAS & \\
\hline 01675 & $\begin{array}{l}\text { Salpingooforect. } \\
\text { Der. Apendicect. } \\
\text { profiláctica }\end{array}$ & 2 & 21 & 37.3 & 21 & $\begin{array}{l}\text { G.6 P.4 - Hace dos años operada por ectópico izq. } 32 \text { años. Metro- } \\
\text { rragia desde hace } 1 \text { mes, dolor hipogástrico, peso rectal. Punción } \\
\text { del Douglas positiva. }\end{array}$ \\
\hline 01961 & Salpingooforect. Izq. & 3 & 16 & 38.5 & 40 & $\begin{array}{l}\text { G.4 P.3 - } 25 \text { años. Metrorragia desde hace } 3 \text { días. Fondo de saco } \\
\text { de Douglas doloroso. Hematosalpinx Izquierdo. }\end{array}$ \\
\hline 01691 & Salpingooforect. Der. & 3 & 20 & 38.1 & 28 & $\begin{array}{l}\text { G.11 P.10 - } 39 \text { años. En cavidad abdominal líquido serosanguíneo } \\
\text { y coágulos. Adherencias. Feto de } 7 \mathrm{cms} \text {. Raquianestesia y al final } \\
\text { pentotal para el cierre de los planos. }\end{array}$ \\
\hline 01818 & $\begin{array}{l}\text { Salpingect. Derecha } \\
\text { Apendicect. profil. }\end{array}$ & 4 & 17 & - & - & $\begin{array}{l}\text { G.4 P.2 A.1 - } 28 \text { años. Metrorragia de regular intensidad durante } \\
1 \text { semana. Curetaje por considerarse aborto incompleto, restos } \\
\text { mal olientes. Entró a cirugía con temperatura } 38.9^{\circ} \text { Gran canti- } \\
\text { dad de coágulos negros. Encerrado en sus membranas feto de } 20 \\
\mathrm{cms} \text {. Placenta incertada en porción istmica trompa derecha, en } \\
\text { parte desgarrada. Hematíes: } 2.700 .000 \text {. Hemog.: } 40 \% \text {. Embara- } \\
\text { zo Istmico abdominal. }\end{array}$ \\
\hline 02316 & Salpingect. Derecha & 2 & 18 & 37.6 & 48 & $\begin{array}{l}\text { G.4 P.3 - } 24 \text { años. Sintomatología } 4 \text { días antes. Punción de Dou- } \\
\text { glas positiva. Coágulos y sangre líquida en abdomen. Se visualiza } \\
\text { huevo formando tumoración en trompa derecha. Se hace necesa- } \\
\text { rio completar anestesia con pentotal. }\end{array}$ \\
\hline 03025 & Salpingect. Derecha & 3 & 7 & 37.8 & 60 & $\begin{array}{l}\text { G.6 P.4 A.1 - } 33 \text { años. Sintomatología desde } 13 \text { días. Curetaje } \\
\text { por considerarse aborto incompleto. Punción de Douglas positiva. } \\
\text { Sangre líquida y coágulos en abdomen. Se hizo raquianestesia, } \\
\text { pentotal y éter. }\end{array}$ \\
\hline 3.643 & $\begin{array}{l}\text { Salpingect. Derecha } \\
\text { Apendicect. profil. }\end{array}$ & 8 & 3 & 37.5 & 36 & $\begin{array}{l}\text { G.4 P.3 - } 27 \text { años. Pesó } 41.3 \text { klg. Talla: } 1.46 \mathrm{cms} \text {. Metrorragia } \\
\text { desde } 16 \text { días antes. Punción de Douglas positiva. Abundante san- } \\
\text { gre líquida y coágulos en abdomen. Hematíes: } 2.680 .000 \text {. He- } \\
\text { mog.: } 45 \% \text {. }\end{array}$ \\
\hline
\end{tabular}


CUADRO N $N^{\circ} 2$

Embarazos ectópicos rotos. - Hematosalpinx

\begin{tabular}{|c|c|c|c|c|c|c|}
\hline \multirow{2}{*}{ HIST. N No } & \multirow{2}{*}{ INTERVENCIONES } & \multicolumn{4}{|c|}{ POST. OPERAT. Mx. TEMPERAT. } & \multirow[b]{2}{*}{ OBSERVACIONES } \\
\hline & & DIAS & HORAS & GRADO & HORAS & \\
\hline 3.391 & $\begin{array}{l}\text { Salpingect. Derecha } \\
\text { Apendicect. profil. }\end{array}$ & 2 & 17 & - & - & $\begin{array}{l}\text { Primigrávida. } 22 \text { años. Pesó } 40 \mathrm{klg} \text {. Talla: } 1.56 \mathrm{cms} \text {. Una sema- } \\
\text { na antes hospitalizada en malas condiciones generales por provoca- } \\
\text { ción de aborto. Se hizo transfusión y dio de alta mejorada. Regre- } \\
\text { só en peores condiciones, siendo intervenida. Abundante sangre } \\
\text { en abdomen Entró a cirugía con temperatura } 38.5^{\circ} \text { desaparecien- } \\
\text { do antes de las } 24 \text { horas. Hematocrito: } 19 \% \text {. }\end{array}$ \\
\hline A.M.Z. & $\begin{array}{l}\text { Slpingect. bilateral } \\
\text { Enucleación quiste } \\
\text { ovario derecho }\end{array}$ & 2 & 21 & 38 & 28 & $\begin{array}{l}\text { G.7 P.6 - } 35 \text { años. Pequeñas metrorragias desde hace } 1 \text { mes. } \\
\text { Buen estado general. Hematosalpinx izquierdo. Salpingitis quística } \\
\text { derecha. Quiste de ovario derecho. }\end{array}$ \\
\hline $\begin{array}{l}\text { A. J. } \\
\text { de S. }\end{array}$ & Salpingect. Izq. & 1 & 19 & 38.5 & 4 & $\begin{array}{l}33 \text { años. Sintomatología dolorosa desde una semana antes. Pun- } \\
\text { ción de Douglas positiva. Entra a cirugía con } 38^{\circ} \text { temp. Abundan- } \\
\text { te sangre en cavidad abdominal. Se liberan adherencias. Hemato- } \\
\text { salpinx izquierdo. La temperatura descendió a } 37.5^{\circ} \text { a las } 19 \text { ho- } \\
\text { ras. Terramicina: } 250 \mathrm{mmg} \text {. en sol. fisiológica } 30 \text { c.c. }\end{array}$ \\
\hline L.P.C. & Salpingect. Izq. & 1 & 16 & 37.8 & 24 & $\begin{array}{l}\text { G.4 P. } 3 \text { - Sir tomatología metrorrágica y dolorosa desde hace } 3 \\
\text { días. Edad: } 25 \text { años. Punción de Douglas positiva. Coágulos y san- } \\
\text { gre líquida en cavidad abdominal. Hematosalpinx izquierdo. He- } \\
\text { mog.: } 7 \text { gr. Hematocrito: } 20 \% \text {. Terramicina: } 250 \text { mmg. en } 30 \\
\text { c.c. sol. fisióógica. }\end{array}$ \\
\hline
\end{tabular}


CUADRO N: 3

Varios

\begin{tabular}{|c|c|c|c|c|c|c|c|}
\hline \multirow{2}{*}{ HIST. № } & \multirow{2}{*}{ CAUSA } & \multirow{2}{*}{ INTERVENCIONES } & \multicolumn{2}{|c|}{ POST. OPERAT. } & \multicolumn{2}{|c|}{ Mx. TEMPERAT. } & \multirow{2}{*}{ OBSERVACIONES } \\
\hline & & & DIAS & HORAS & GRADO & HORAS & \\
\hline 02159 & Perforación uterina & Histerorafia & 2 & 7 & 37.7 & 16 & $\begin{array}{l}\text { Al practicar curetaje por aborto incompleto se provoca la perfo- } \\
\text { ración. } 1.5 \mathrm{cms} \text {. en fondo. Se sutura con catgut. }\end{array}$ \\
\hline 01622 & Perforación uterina & $\begin{array}{l}\text { Histerorafia } \\
\text { Resección cuneiforme } \\
\text { armbos ovarios }\end{array}$ & 2 & 18 & 37.8 & 28 & $\begin{array}{l}\text { Paciente pensionada. Sangre considerable y coágulos en abdomen. } \\
\text { Hacia cuerno izq. perforación } 1 \mathrm{~cm} \text {. Entre ligamentos útero sa- } \\
\text { cros otra perforación de } 2 \mathrm{cms} \text {. anfractuosa. }\end{array}$ \\
\hline 01458 & $\begin{array}{l}\text { Quiste ovario } \\
\text { derecho }\end{array}$ & Ooforectomía & 1 & 22 & 37.5 & 30 & \\
\hline 02422 & $\begin{array}{l}\text { Quiste ovario lzq. } \\
\text { con pedículo torcido }\end{array}$ & Ooforectomía & 4 & 9 & - & - & $\begin{array}{l}\text { Sintomatología dos días antes. Llega a cirugía con } 39.8^{\circ} \text { temp. Al } \\
\text { abrir peritonso cae en shock impidiendo continuar durante } 15 \mathrm{mi}- \\
\text { rutos. Se transfundió sangre } 500 \text { c.c. Quiste azuloso con pedículo } \\
\text { algo necrótico. }\end{array}$ \\
\hline 00405 & $\begin{array}{l}\text { Absceso Anexo } \\
\text { Derecho }\end{array}$ & $\begin{array}{l}\text { Salpingooforectomía } \\
\text { Apendicectomía }\end{array}$ & 2 & 21 & 38.2 & 48 & $\begin{array}{l}\text { Curetaje por aborto incompleto. Regresa a la semana con sínto- } \\
\text { mas de absceso pélvico. Colpotomía posterior que no llena su co- } \\
\text { metido. Posteriormente cirugía: fuertes adherencias. Se drena el } \\
\text { absceso. Terramicina: } 500 \mathrm{mmg} \text {. Apendicectomía. }\end{array}$ \\
\hline 01684 & $\begin{array}{l}\text { Pelviperitonitis } \\
\text { Aguda }\end{array}$ & $\begin{array}{l}\text { Inyección a través } \\
\text { de!! Douglas }\end{array}$ & 1 & 21 & - & - & $\begin{array}{l}\text { Temperatura } 39.5^{\circ} \text { Dolor difuso en hipogastrio con resistencia mus- } \\
\text { cular. Punción del Douglas: líquido seropurulento. Por la misma } \\
\text { váa se dejan } 250 \mathrm{mmg} \text {. Terramicina a las } 2 \mathrm{p} \text {. } \mathrm{m} \text {. A las } 4 \mathrm{a} \text {. m. } \\
\text { del siguiente día, temperatura } 36.5^{\circ} \text { Desapareció dolor e igual- } \\
\text { mente una blefaritis bilateral. }\end{array}$ \\
\hline 02426 & $\begin{array}{l}\text { Piosalpinx } \\
\text { Bilateral }\end{array}$ & $\begin{array}{l}\text { Salpingect. Der. } \\
\text { Salpingooforect. } \\
\text { Izq. Histerectomía } \\
\text { total }\end{array}$ & 5 & 20 & 39 & 48 & $\begin{array}{l}\text { Numerosas adherencias. Los abscesos derraman en la cavidad ab- } \\
\text { dominal al liberarlos. La intervención duró } 3 \text { hroas. Anestesia pe- } \\
\text { ridural, además, pentotal y éter. Al finalizar la paciente cayó en } \\
\text { shock, recuperándose al cabo de dos horas mediante transfusio- } \\
\text { nes. Se dejó } 500 \mathrm{mmg} \text {. Terramicina. }\end{array}$ \\
\hline
\end{tabular}


CUADRO No 3

Varios

\begin{tabular}{|c|c|c|c|c|c|c|c|}
\hline \multirow[b]{2}{*}{ HIST. N No } & \multirow[b]{2}{*}{ CAUSA } & \multirow[b]{2}{*}{ INTERVENCIONES } & \multirow{2}{*}{\multicolumn{2}{|c|}{\begin{tabular}{l|l}
\multicolumn{2}{|c|}{ POST. } \\
OPERAT. \\
DIAS & HORAS
\end{tabular}}} & \multicolumn{2}{|c|}{ Mx. TEMPERAT. } & \multirow[b]{2}{*}{ OBSERVACIONES } \\
\hline & & & & & GRADO & HORAS & \\
\hline 03238 & $\begin{array}{l}\text { Quiste ovario } \\
\text { Izquierdo }\end{array}$ & $\begin{array}{l}\text { Ooforectomía } \\
\text { Apendicect. prof. }\end{array}$ & 1 & 22 & - & - & \\
\hline 01423 & Tumor Previo & $\begin{array}{l}\text { Cesárea Segm. } \\
\text { Histerect. total }\end{array}$ & 2 & 20 & 37.4 & 52 & $\begin{array}{l}\text { G.7 P.5 - } 31 \text { años. Embarazo a término. T. de parto. A través } \\
\text { del cuello masa dura, sésil, del tamaño del puño. Histerectomía } \\
\text { total, previa cesárea segmentaria. Hematíes: } 1.860 .000 \text {. Hemato- } \\
\text { crito: } 16 \%\end{array}$ \\
\hline 02849 & $\begin{array}{l}\text { Quiste dermoide } \\
\text { Salpingitis } \\
\text { quística Izq. }\end{array}$ & $\begin{array}{l}\text { Salpingooforect. Izq. } \\
\text { Resección cuneiforme } \\
\text { ovario Der. } \\
\text { Apendicect. prof. }\end{array}$ & 3 & 22 & 38.3 & 6 & \\
\hline 01870 & Endometrioma? & $\begin{array}{l}\text { Ovariectom. Der. } \\
\text { Apendicectomía }\end{array}$ & 2 & 19 & 37.6 & 4 & $\begin{array}{l}\text { Hace } 6 \text { años salpingoplastia y resección cuneiforme ambos ova- } \\
\text { rios. Hay gren cantidad de adherencais. Se punciona el quiste de } \\
\text { contenido achocolatado y se extirpa la bolsa. Raquianestesia que } \\
\text { termina con pentotal. }\end{array}$ \\
\hline 3.191 & Absceso Pélvico & $\begin{array}{l}\text { Histerect. total } \\
\text { Salpingooforect. } \\
\text { Izq. Salpingect. Der. }\end{array}$ & 2 & 21 & 38.2 & 48 & $\begin{array}{l}\text { Talla: } 1.54 \text { Peso: } 48 \mathrm{klg} \text {. Vómitos el mismo día de operada con } \\
\text { expulsión de numerosos áscaris. Durante la nitervención el absce- }\end{array}$ \\
\hline 02869 & $\begin{array}{l}\text { Endometrioma? } \\
\text { Quiste luteínico }\end{array}$ & $\begin{array}{l}\text { Resección cuneif. } \\
\text { Ovar. Der. Apen- } \\
\text { dicect. profiláct. }\end{array}$ & 1 & 20 & 37.4 & 4 & \\
\hline G.Z.V. & Absceso pélvico & $\begin{array}{l}\text { Aspiración. Salpin- } \\
\text { gooforect. Der. }\end{array}$ & 4 & 16 & - & - & $\begin{array}{l}\text { Edad } 18 \text { años. } 40 \mathrm{klg} \text {. de peso. Aborto provocado mediante son- } \\
\text { da. En cavidad abdominal derrame de pus mal oliente; aspirán- } \\
\text { dose casi 1. Apelotonamiento de asas intestinales que conservan } \\
\text { su disposición anatómica. Temperatura } 39.5^{\circ} \text { que cayó definiti- Tou } \\
\text { vamente a las } 60 \text { horas. Por la gravedad en principio se le apli- } \\
\text { có en venoclisis } 250 \mathrm{mmg} \text {. más de terramicina. }\end{array}$ \\
\hline
\end{tabular}




\section{CUADRO No 3}

\section{Varios}

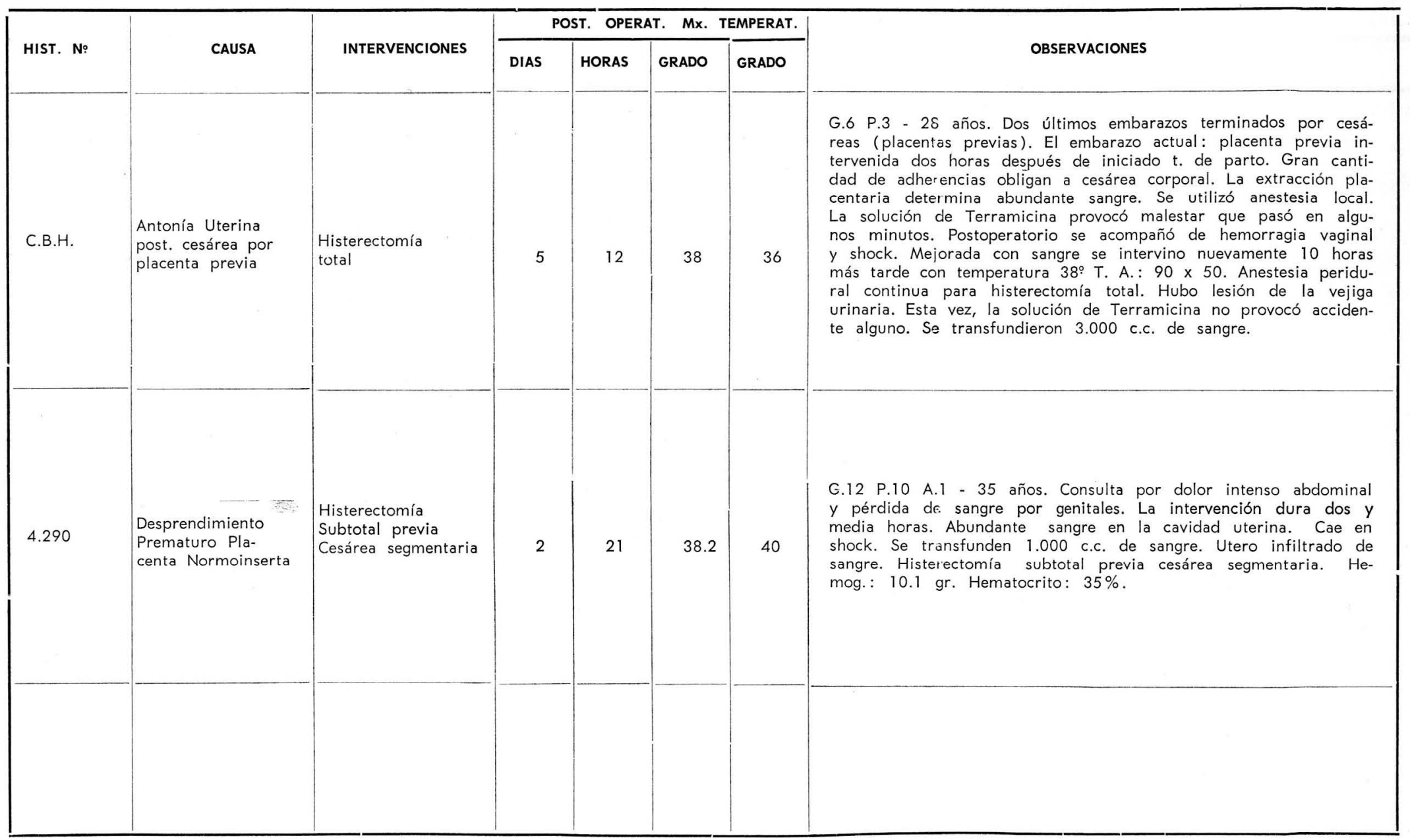


CUADRO Nং 4

Totales parciales

\begin{tabular}{|c|c|c|c|c|c|c|c|c|}
\hline \multirow{2}{*}{ INTERVENCIONES } & \multirow{2}{*}{$\begin{array}{l}\text { No DE } \\
\text { CASOS }\end{array}$} & \multirow{2}{*}{$\begin{array}{l}\text { PORCEN- } \\
\text { TAJES }\end{array}$} & \multicolumn{2}{|c|}{ POSTOPERATORIO } & \multicolumn{3}{|c|}{ TIEMPO PROMEDIO } & \multirow{2}{*}{$\begin{array}{c}\text { HORAS } \\
\text { PROMEDIO }\end{array}$} \\
\hline & & & DIAS & HORAS & DIAS & HORAS & MINUT. & \\
\hline Cesáreas Segm. & 23 & $46 \%$ & 72 & 8 & 3 & 3 & 30 & $751 / 2$ \\
\hline Ectópicos etc. & 11 & $22 \%$ & 33 & 12 & 3 & 1 & 05 & $73.05^{\prime}$ \\
\hline Varios & 16 & $32 \%$ & 51 & 3 & 3 & 4 & 41 & $76.41^{\prime}$ \\
\hline \multicolumn{9}{|c|}{ CUADRO N 5} \\
\hline Gran Total & 50 & $100 \%$ & 156 & 23 & 3 & 3 & 20 & $75.1 / 4$ \\
\hline
\end{tabular}


casos de abscesus pélvicos, quistes de ovario, perforaciones uterinas por curetajes, histerectomías etc. En las respectivas columnas anotamos los días y horas del postoperatorio de acuerdo con lo indicado anteriormente a este respecto, causa y tipo de intervención, como también el más alto grado de temperatura alcanzado y el número de horas transcurrido al producirse esta hipertermia. La última columna recoge los antecedentes y un resumen de las condiciones pre y postoperatorias. Finalmente, los cuadros 4 y 5 agrupan en forma parcial y total los datos generales de este estudio.

No queremos alargarnos en comentarios sobre las historias y cuadros que presentamos, ya que nada agregaríamos a su objetividad. Queremos sí recalcar el beneficio obtenido con este tratamiento que permitió una permanencia hospitalaria promedio de solo 3 días, 3 horas y 20 minutos por paciente en 50 casos, muchos de los cuales de notable gravedad; y la mayoría en pésimas condiciones preoperatorias.

\section{RESUMEN}

1) Se presentan 50 casos de diferentes intervenciones laparotómicas obstétrico-ginecológicas, en las cuales se dejó 250-500 mgm. de terramicina tipo endovenoso en 15-20 y 30 centímetros de dextrosa al $5 \%$ en agua destilada y en solución fisiológica, en la cavidad abdominal.

2) Se revisa la literatura sobre la Terramicina intraperitoneal. Observamos que la misma se refiere al tratamiento de la peritonitis generalizada mediante perfusión abdominal.

3) Se presenta un caso en el cual se usó la Terramicina en 15 c.c. de solución inyectada a través del fondo de saco de Douglas.

4) Se acompañan dos cuadros estadísticos que revelan la bondad del procedimiento.

\section{CONCLUSIONES}

1) La Terramicina en solución dejada en la cavidad abdominal es un procedimiento completamente inocuo y altamente eficaz en la prevención de la morbilidad post-operatoria. 
2) Permite acortar notablemente el internamiento postoperatorio hospitalario.

3) Permite por lo tanto, mayor aprovechamiento del cupo hospitalario a un costo menor por paciente y un gasto de antibióticos reducido al mínimo.

4) El estado general del paciente dentro de las primeras 24 horas es más satisfactorio, aceptando con confianza la movilización precoz.

5) Solo se presentaron dos complicaciones por bronconeumonía, lo que obligó al uso de antibióticos por vía parenteral.

6) Este tratamiento no debe utilizarse en los casos intervenidos con anestesia local por dar origen a percances desagradables.

Nuestros agradecimientos al personal Científico de Clínica de Maternidad Doctores: José María Pérez Ruiz, Orlando Castillo C., Boris Calvo del Río y Roberto Dickson.

\section{BIBLIOGRAFIA}

1) BONILLA NAAR A., ALVAREZ VASQUEZ A. Tratamiento Racional de la Peritonitis Generalizada. Rev. Med. y C.irugía Vol. XXIV. № 5. Oct.-Nov. 1960.

2) SCHATTENN W. E. Intraperitoneal Antibiotic Administration. Surg. Gynec. and Obst. 102 Marzo/56.

3) DI CARLO G. Terramycin Therspy. Pág. 109. Editor Medical Department of Pfizer Laboratories.

4) EDER W. P. and MYERS N. L. Terramycin Therapy. Pág. 110. Editor Medical Department of Pfizer Laboratories. 1960. U.S.A.

5) SCHATTENN W. E. and ABBOTT W. E. Terramycin Therapy. Pág. 109. Editor: Medical Department of Pfizer Lab. 1960. U. S. A. 